\title{
Diffuse lung infiltration in a homosexual man without AIDS
}

\author{
RICHARD POHIL, MD \\ PHILIP MAPLE, MD \\ GILBERT D'ALONZO, DO
}

\begin{abstract}
Homosexual men who present with respiratory complaints and diffuse lung infiltrates on chest $x$-ray generally have the AIDS syndrome and an ongoing opportunistic pneumonia. In the case presented, the usual diagnosis was not found and the patient's lung infiltrates and symptoms were due to drug-induced eosinophilic pneumonia. This case report demonstrates that not all homosexual men who present with the usual clinical picture for AIDS have AIDS and that not all diffuse lung infiltrates are infectious in etiology.
\end{abstract}

A homosexual man with diffuse pulmonary infiltrates, cough, and hypoxemia usually is thought to have acquired immunodeficiency syndrome (AIDS). In such cases, the pulmonary infiltrates are considered to be of infectious origin; Pneumocystis carinii, ${ }^{1}$ cytomegalovirus, ${ }^{2}$ and nontubercular mycobacterial infections ${ }^{3}$ generally are suspected.

The case reported here demonstrates that not all homosexual men who present with the classic clinical picture have AIDS, and that not all diffuse lung infiltrates are infectious in etiology.

\section{Report of case}

A 25-year-old homosexual man was admitted in August 1984 for evaluation of a productive cough with clear sputum, bilateral pleuritic chest pain, and exertional dyspnea of two weeks' duration.

Several days prior to the onset of these symptoms, a sore throat, coryza, and an oral ulceration were noticed by the patient. Oral cephalosporin therapy was prescribed, but it was discontinued after a single dose when urticaria developed. Next, tetracycline $(500 \mathrm{mg}$, four times a day) was prescribed and taken for approximately one week. All three symptoms improved in two to three days, but as they resolved, cough, chest pain, and dyspnea appeared and then worsened. The patient had reinstituted tetracycline therapy for approximately 48 hours prior to hospital admission.

The medical history revealed that in March 1983, the patient experienced an illness characterized by diarrhea, weight loss of approximately $10 \mathrm{lb}$, and generalized malaise. Mild leukopenia and anemia also were present. Although definite diagnosis was not determined, the illness resolved spontaneously.
Physical examination on admission revealed the patient to be well developed and healthy appearing. The oral temperature was $100^{\circ} \mathrm{F}$, and the respiratory rate was 22 breaths/min; otherwise, his vital signs were normal. Bibasilar mid-to-end inspiratory crackles were heard on auscultation. There was no evidence of adenopathy, abdominal organ enlargement, or skin lesions, and the oral and rectal examinations had normal findings.

Diffuse, bilateral, interstitial-alveolar infiltrates were demonstrated on the chest roentgenogram (Fig 1). The electrocardiogram was normal. Values for arterial $\mathrm{PO}_{2}$, $\mathrm{PCO}_{2}$, and $\mathrm{pH}$ were $60 \mathrm{~mm} \mathrm{Hg}, 34 \mathrm{~mm} \mathrm{Hg}$, and 7.41 , respectively. The peripheral leukocyte count was 12,000 / cu $\mathrm{mm}$. The differential count included $66 \%$ eosinophils; the total eosinophil count was $80,000 / \mathrm{cu} \mathrm{mm}$.

Based on presumptive diagnosis of Pneumocystis carinii pneumonia, the patient initially was treated with an intravenous trimethoprim and sulfamethoxazole combination. The next morning, approximately 14 hours following admission, bronchoscopy, bronchoalveolar lavage, and multiple transbronchial biopsy were performed under fluoroscopic guidance.

Histologic examination of the biopsy specimens revealed only marked eosinophilic infiltration (Fig 2). Bronchoalveolar lavage failed to reveal an infectious etiology. Routine and special cultures for fungus, virus, Chlamydia, Mycoplasma, Legionella, and Mycobacterium were negative. Stool specimens, as well as a duodenal aspirate, failed to demonstrate ova or parasites. There was no deficiency of helper T-lymphocytes, and the Tcell helper/suppressor ratio in the peripheral blood was normal.

Following the fiberoptic bronchoscopy, antibiotic therapy was discontinued, and steady improvement of both clinical and laboratory parameters occurred. Subsequently, a chest film reflected clearing of the lung infiltrates (Fig 3), and arterial blood gas values had normalized. Eight days after admission, immediately prior to discharge, the peripheral total eosinophil count decreased to 1,000 cells/cu mm.

At follow-up examination four months later, the patient's chest roentgenogram, arterial blood gas levels, and $\mathrm{CBC}$ (including peripheral smear) were normal. Two years after discharge, he remained asymptomatic, and serologic testing for human immunodeficiency virus was negative.

\section{Discussion}

Since the recognition of AIDS in 1981, the disease 


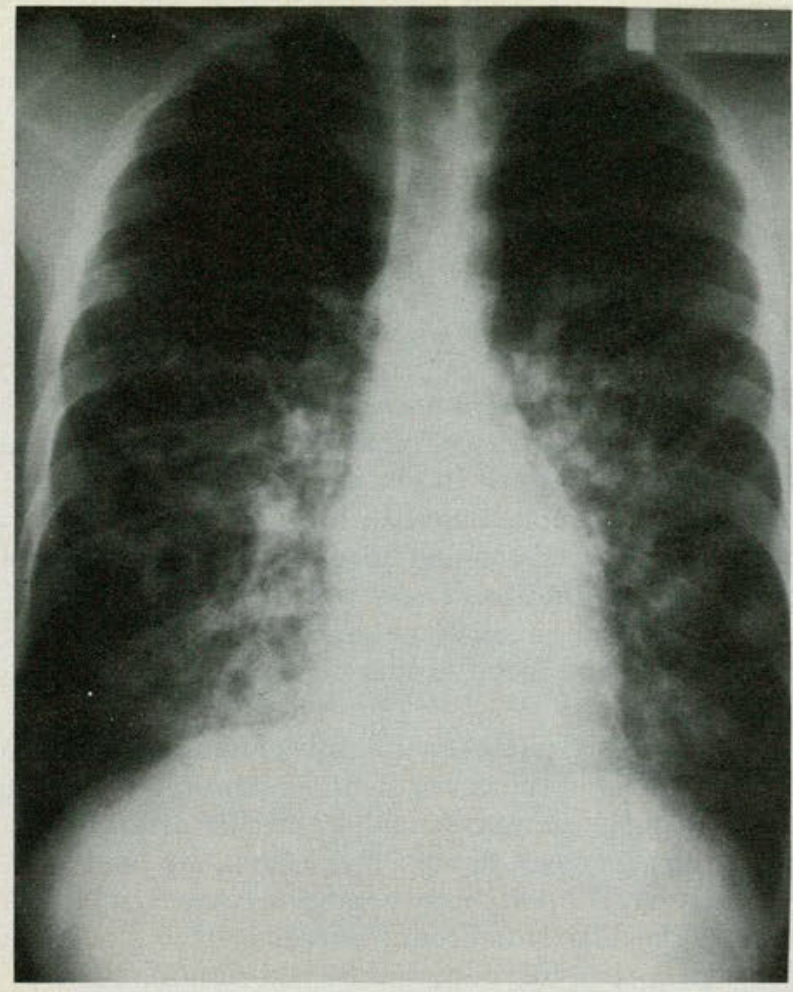

Fig 1. Admission chest roentgenogram reveals bilateral interstitial alveolar infiltrates.

has maintained its position as one of the most fascinating, yet worrisome, topics in pulmonary medicine. According to the Centers for Disease Control, AIDS can be diagnosed when a high-risk patient with either Kaposi's sarcoma or an opportunistic infection such as $P$ carinii pneumonia is found to have serious underlying immunodeficiency. ${ }^{2-4}$

Other opportunistic infections include cytomegalovirus, candidiasis, Cryptococcus neoformans, herpes simplex and herpes zoster, mycobacterial infection, cryptosporidiosis, and toxoplasmosis. ${ }^{5}$ Nonspecific symptoms and signs, including fever, lymphadenopathy, and weight loss, may or may not be present.

Besides the two major risk groups of male homosexuals or bisexuals and intravenous drug abusers, additional risk subgroups include hemophiliacs and other blood product transfusion recipients, as well as sexual partners and infants of high-risk group members. ${ }^{6}$

Immunologic abnormalities in AIDS include a selective deficit of helper T-lymphocytes, reversal of the T-cell helper/suppressor ratio in the peripheral blood, elevated levels of serum immunoglobulin from polyclonal B-cell activation, and cutaneous anergy. ${ }^{3,4}$

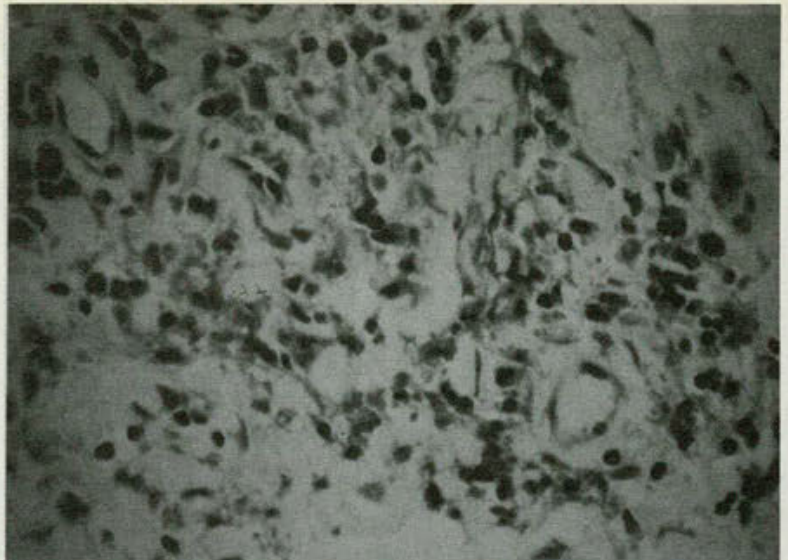

Fig 2. Histologic specimen demonstrates marked eosinophilic infiltration ( $H$ and $E$ stain, original magnification, $\times 400$ ).

The clinical presentation of our patient was strikingly similar to that of many patients with AIDS, that is, high-risk status, cough, dyspnea, fever, weight loss, hypoxemia, and bilateral lung infiltrates. There was no evidence of immunodeficiency or the presence of an opportunistic infection, but marked blood and lung eosinophilia was found. This case presentation demonstrates that diffuse infiltrates in homosexual men are not necessarily due to infectious opportunistic pneumonia, and that the differential diagnosis must be expanded to include other diseases.

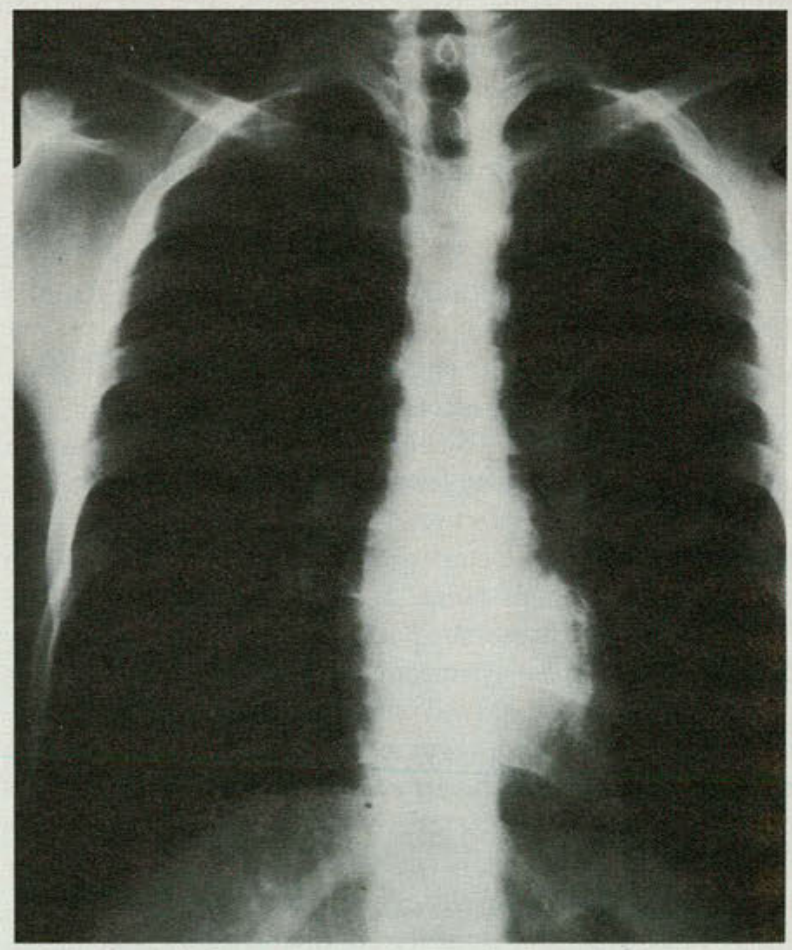

Fig 3. Chest film obtained eight days following admission shows marked clearing of bilateral lung infiltrates. 
The list of diseases associated with bilateral lung infiltrates and eosinophilia has grown substantially since the initial descriptions by Loffler ${ }^{7}$ in 1932 . Recently, Lynch and Flint ${ }^{8}$ categorized these dieases into seven distinct syndromes: eosinophilic pneumonia, chronic eosinophilic pneumonia, parasitic eosinophilic pneumonia, allergic bronchopulmonary aspergillosis, bronchocentric granulomatosis, mucoid impaction of bronchi, and allergic angiitis and granulomatosis. The clinical course and histologic characteristics of the lung biopsy allowed us to classify our case as acute eosinophilic pneumonia.

Recently, this type of pneumonic process has been linked with exposure to various drugs and chemical agents, including penicillin, ${ }^{9}$ nitrofurantoin, ${ }^{10}$ and tetracycline. ${ }^{11,12}$ Although the exact etiology of our patient's disease process remains questionable, the possibility of tetracycline causing the eosinophilic process must be considered.

\section{Summary}

Diffuse lung infiltrates in a homosexual man generally represent opportunistic infection; however, in the case presented this was not true. Obtaining a specific diagnosis is essential for the proper management and treatment of patients who present with diffuse lung infiltrates.
1. Jaffe HW, Choi K, Thomas PA, et al: National case-control study of Kaposi's sarcoma and Pneumocystis cariniipneumonia in homosexual men: Part I —epidemiological results. Ann Intern Med 1983;99:145-151. 2. Mintz L, Drew WL, Miner RC, et al: Cytomegalovirus infections in homosexual men: An epidemiological study. Ann Intern Med 1983;99:326329.

3. Murray JF, Felton CP, Garay SM, et al: Pulmonary complications of the acquired immunodeficiency syndrome: Report of a National Heart, Lung, and Blood Institute Workshop. N Engl J Med 1984;310:16821688 .

4. Groopman JE: Kaposi's sarcoma and other neoplasms. Ann Intern Med 1983;99:208-210.

5. Update on acquired immune deficiency syndrome (AIDS)-United States. MMWR 1982;31:507-514.

6. Chamberland ME, Castro KG, Haverkas HW, et al: Acquired immunodeficiency syndrome in the United States: An analysis of cases outside high-incidence groups. Ann Intern Med 1984;101:617-623.

7. Loffler W: Zur Differential Diagnose der Lungenin Filtrierungen: III. Uber Fluchtige Succedan Infiltrate (mit Eosinophilie). Beitr Klin Tuberk 1932;79:368-392.

8. Lynch JP III, Flint A: Sorting out the pulmonary eosinophilic syndromes. J Resp Dis 1984;5(July):61-78.

9. Reichlin S, Loveless MH, Kane EJ: Loeffler's syndrome following penicillin therapy. Ann Intern Med 1953;38:113-120.

10. Hailey FJ, Glascock HW Jr, Hewitt WF: Pleuropneumonic reactions to nitrofurantoin. $N$ Engl J Med 1969;281:1087-1090.

11. Ho D, Tashkin DP, Bein ME, et al: Pulmonary infiltrates with eosinophilia associated with tetracycline. Chest 1979;76:33-36.

12. Otero M, Goodpasture HC: Pulmonary infiltrates and eosinophilia from minocycline, letter. JAMA 1983;250:2602.

From the Department of Internal Medicine, Division of Pulmonary Medicine, University of Texas Medical School, Houston, Tex.

Reprint requests to Dr D'Alonzo, 5431 Fannin, Suite 1.274, Houston, TX 77030 . 